\title{
Product Lifestyle Design: Innovation for Sustainability
}

\author{
Rinaldo C. Michelini and Roberto P. Razzoli \\ PMARlab, University of Genova, Italy, \{michelini\|razzoli\}@dimec.unige.it
}

\begin{abstract}
The product lifestyle design is necessary sustainable growth accomplishment, enforced by the enacted eco-regulations. The paper discusses the incumbent restructuring of the manufacturing companies, recalling the innovation at the design phase, by effective product-process-environment-enterprise, 2P2E, integration, supported by suitably detailed modelling and simulation features, $M \& S F$, leading to information intensive value chains based on: - net-concerns, gathering and enabling business set-ups, from the facility/function market; - service dealers, for the extended enterprise added value operations; - recovery rulers, for reverse logistics accomplishments and tasks overseeing. A short outlook of the topics is sketched, and, for explanatory purposes, example developments are recalled, referred to industrial situations emerging from the recent EU environmental policy.
\end{abstract}

Keywords: Lifestyle design, Modelling \& Simulation features, Reverse logistics, Extended enterprise, Lifecycle diagnostics

\section{Introduction}

The product design methodologies and practices are expected to face in the short future important changes, to deal with the lifestyle requirements of the growth sustainability, spurred by the enacted rules of the EU environmental policy. The future to come suggests that competition shall take place, under market regulatory conditions different from now, to grant environmentally more conservative goals $[1,2]$. In this vision, producers' responsibilities are widened, and products information needs to extend across the supply chain, to cover lifecycle and recovery. The changes aims at granting visibility at the points-of-service, in connection with the on-duty conformance-to-specification tests, and at the end-oflife, to comply with the enacted recovery (reuse, recycle) rules.

The innovation develops along paired lines, where competitiveness will depend on entrepreneurship founded on economies of scope, ruled by extended enterprises, offering product-service combinations. Combined modelling and simulation are the winning tools, to expand the supply chain visibility, keeping unified accountability of the lifecycle properties. The materials, process, operation, maintenance, dismissal and recycling figures are tested and assessed by virtual prototypes, during the design phases. As compared to earlier industrial habits, when competition was won by the off-process presetting and optimal production plans, today enhanced decision support is required to run on-process, aiming at [3]:

- product quality for customised requests and minimal environment impact; 
- manufacture choice for process robustness, to preserve the throughput quality;

- service schedules for conformance-to-use maintenance, as supply chain option;

- end-of-life take-back, with recovery rules, within the enacted mandatory targets.

The growth eco-sustainability charges, brought on by (passed or visibly declared) acts are thought troubles to defer to the future to come, by short-sighted companies. The worldwide competitors have consciousness of the above prospects, and arrange information intensive value chains, incorporating:

- off-process condition knowledge data-bases, caring for products lifestyle design;

- real-time diagnosis and decision tools, designed as on-duty service complements;

- recovery functions and facilities, assuring compulsory reverse logistics duties.

The paper offers a bird-eye overview of these lines, to address the design practice requirements, by multi-disciplinary approach, with concern of on hand CAD tools that embed algorithmic and heuristic blocks to offer mixed mode simulation-andemulation, and product lifecycle management aids that look at service engineering and reverse logistics, to tackle with the on-duty and recovery tasks provision.

\section{Integrated Design for Lifestyle Innovation}

The industrial economy exploits the manufacture efficiency for the wide trade of low cost goods, obtained transforming raw materials into waste and pollution. The growth sustainability requires deep changes, for better resource exploitation by recovery and remediation practices. This means restructuring the companies' businesses, moving the producers/sellers responsibility, from the point-of-sale, to the points-of-service, and to the take-back of end-of-life items. The corporations' competition has to turn from the product suitability (by scale-economy) and the process fitness (by simultaneous engineering), to the environmental protection (by ecology stability) and the enterprise aptness (by function/facility trimming). The change requires dramatic up-dating, with the new scope-economy, quickly moving from the shop internalities of the conventional «firm theory» (the makeor-buy dilemma), to the supply chain externalities of the product life and callback duties $[4,5,6]$.

The world-class companies are compelled to re-orient the business value chain on trading products-services, with the latter extension object, in some case, of extra voluntary agreements, drawn up with the clients, in other case, of fixed mandatory targets, enacted by the governs. Indeed, the technical choices, allowing to put in the market a product, are, always, manufacturers' responsibility, with decisions taken at the design phase. Thus, the winning innovation, assuring the competitive advantage to one or the other company, has to played at the lifestyle levels, by warranting utmost on-duty performance and recovery abilities to the offers, the all to be proved out of the conventional productive shops. These new scopes request:

- to preset product lifecycle management, PLM, tools, as standard design out-fit;

- to provide the service engineering, SE, for diagnosis, decision and maintenance;

- to fulfil the reverse logistics, RL, when compulsorily enacted at the end-of-life.

The business widening, around the whole product-service, is sought with resort to enhanced PLM tools, with federated architecture, assuring unified access to the lifecycle data. The integration of all the lifecycle views (structure and function 
layout, fabrication process, quality certification, maintenance policy, dismissal duties, etc.) into a super-model is competitive plus, for value chain up-grading.

More specifically, addressing the product design phase as off-process decision support, four domains need to be in-progress tackled by the pertinent integration steps $[7,8]$ :

- product specification, leading to proper performance, selecting, by CAD, CAM, etc. tools: producibility figures, operation constraints, dismissal requests, etc.;

- process specification, leading to better manufacturing value by simultaneous engineering practice of the product-and-process mutual pace-wise up-grading;

- eco-consistency specification, leading to establish regulation, maintenance, restoring, etc. plans, for on-duty conformance-to-use, and to call-back plans;

- enterprise specification, leading to adapt the supply chain with resort to the facility/function integration, matching the in-progress requested externalities.

The design develops, embedding the major modelling and simulation features, $M \& S F$, to cover the four spheres of the product, the process, the environment and the enterprise. The consistent product description through the pertinent $M \& S F$, assures adequate lifestyle characterisation by means of effective virtual checks, fulfilled on relatable digital mock-ups, timely, related to the vitual prototypes of the product or enterprise under test. The cross-linked description permits hierarchical inquiry, giving consistent views of given aspects (operation performance, manufacture goals, eco-conservativeness figures, etc.) at different levels of abstraction and/or lifecycle steps, so that the item designers (and the enterprise managers) readily verify the actually achieved properties, they need to make decisions. The issued super-model, collecting functional models, structural lay-outs, constituent materials, fabrication processes, quality certification, up-keeping policy, recovery requirements, etc., becomes the basic means, to build up the competitiveness of the product-service provision activity [9,10,11].

The four M\&SF ranges expand the conventional PLM tools reaches, to include the service engineering, SE, data into the PLM tools, creating SE-oriented-PLM, or PLM-SE, and to further expand the reverse logistics, RL, figures in the same tools, creating RL-oriented-PLM, or PLM-RL. The M\&SF-driven picture is nice reference of integrated design knowledge frames, with extension towards the ecosustainability challenges, to reach the product-process-environment-enterprise, 2P2E, design, where the lifecycle externalities are dynamically accounted, inprogress adapting the enterprise functions and facilities, whenever new environment requirements appear.

The product-process-environment-enterprise 2P2E design becomes best practice, once the all lifecycle, dismissal included, duties are standard responsibility of manufacturers. This shows the way to the extended enterprises, and the M\&SF description shall evolve to include the business and operation management areas, so that the supply chain externalities are dealt with by simultaneously adapting the enterprise data (taking in the timely useful facilities) to the environmental requests (mandatory targets or voluntary agreements). The task is here more problematic, since the physic-based frames of engineering and manufacture are replaced by economic transactions, human and intellectual activities, social and legal constraints. Objects and events are specified by texts, frames, spreadsheets or graphic trends; model validation and simulation testing quickly lead at data 
reduction in terms of cost propagation and due dates. This provides effective way to acknowledge business and operation functions, and to help providing full visibility for reliable prediction and on-process control and steering actions. The incorporation of appropriate extended enterprise $M \& S F$ is domain open to new developments, where the PLM aids option shall play strategic role, with large resort to declarative and procedural knowledge, and extensive exploitation of the networked infra-structures. At the enterprise-environment integration steps, the use of the net-concern or virtual enterprise options provides enhanced efficacy, especially if the market of productive facilities/functions exist, and the assembling of the co-operating entrepreneurial setting can operate on it [12].

The sketched design metods explain how to deal with the sustainable growth demands, and show how innovation is strictly connected with new information flows, the PLM-SE and PLM-RL, to be established at the design phase, to make effective the service engineering, SE, expanding the business through voluntary agreements, and the reverse logistics, RL, whenever enacted through call-back requirements. The emerging business lines profit of co-operative networked organisations, according to different approaches: on one side, manufacturers could be spurred to keep in charge the all service: artefacts supply, lifecycle conformance and dismissal incumbents, so that the trade regulation would depend on single indentures; on the other side, independent enterprises could profit by safety rules and environment acts expansion, to become service dealers, with technology oriented qualification and infrastructure-based organisations.

Both approaches require to focus on the design phase, built on significant modelling and simulation features, $M \& S F$, moving the enterprise profitability to be critically dependent on the value chain choices, by on-going product-processenvironment-enterprise, $2 \mathrm{P} 2 \mathrm{E}$, adaptive enhancement.

\section{Extended-Enterprise for Lifestyle Innovation}

The joint $2 \mathrm{P} 2 \mathrm{E}$ approach allows to deal with the product-service externalities at the design phase. The environment-enterprise data integration is tough option (not existing in the traditional manufacture practice) progressively required with the expansion of the eco-regulations. In terms of the manufacturers' participation, one has two lifestyle frames [3]: technical responsibility of the on-duty and recovery tasks, even when the points-of-service and -take-back assessments are managed by end users; full (forward and backward) supply chain responsibility over the product-service eco-consistency, to lawfully put in the market of new offers.

In the first case, the producers and the buyers are jointly liable, face to the enacted environment directions. A given offer, of course, has different values at the point-of-sale, depending on the expected lifecycle and end-of-life charges, so that the eco-costs need to be included, when weighing competing proposals. In the second case, the visibility of the eco-fees is not only (implicit or explicit) merit, rather necessary accomplishment to be carried, at the design phase, when assessing the given delivery profitability. The trend is consistent with using the 2P2E frame as constant reference, [8]. An example development is recalled hereafter, [13], for explanatory purposes of extended enterprise's decision support, for the lifecycle pro-active maintenance, ruled through voluntary agreements, [14], with the clients. 
The idea is to grant lifecycle diagnostics and maintenance of widespread durables, with primary goal in conformance-to-use warrantee of the product, and secondary goal in the reliability data collection for reuse and redesign duties. The service engineering, SE, provision is centralised at the manufacturer shop, making use of distributed intelligence and structured communication aids. The lifecycle visibility is initial step, allowing the ensuing decision-frame, to select effective recovery policy in front of the finally privileged EU position. The example deals with the critical situation, in the automotive areas, of the plastic components, which are used, also, for structural items, with strength and reliability requisites so that recycled stuffs are not allowed. The EU policy foreshadows four tracks: - reuse of reconditioned items, once verified safe operation and reliability; - recycle of warnout pieces, with secondary-material certification; - thermal recovery of chosen stuffs, assuring emission eco-compatibility; - reduction to ASR, if the previous options are not met.

The first, only, belongs to the forward supply chain, delaying the item's life end. It deals with the product-service delivery, using embedded and ambient intelligence. The former assures the local knowledge build-up; the latter, its communication management by outer outfits. The recovery by condition monitoring up-keeping aims, [2,3], at:

- proactive regeneration: embedded ability establishes zero-defect on-duty plans;

- reactive restoration: the anomalies are removed at detected/programmed stops.

The embedded diagnostics is of no help, unless suitable regeneration outfits are forecast at the design steps, with additional cost and sophistication. The proactive maintenance complexity and price advise against fully autonomous solutions, and efficient alternative is reactive up-keeping, with remote diagnostics and restoring planning. The concept behind is to have information when you need it, and to plan the service provision by lean rigs. The knowledge-base (e.g., system assumption, reasoning abilities) has remote location, where the process data are transmitted and processed, for inferring diagnoses and feed-forward plans. This facilitates managing the decision for maintenance, trims the charges and lowers the wastes. Remote diagnostics is consistent with reactive restoring, after provisioning the repair equipment, but, also, with basic proactive actions, if the nominal state is brought back to the original conditions by the embedded redundancy, so that the renovation is enabled by 'switching-and-play' options. With focus on condition monitoring, $[13,3]$, the basic actions are:

- to detect/identify the abnormal situations, shown by operation features or drifts;

- to assess crash situations, defective components, fault level, failure type, etc.;

- to troubleshoot, assessing restoring policy and replacing/maintenance duties.

The development of the central diagnostic knowledge demands big efforts. The profitably depends on each situation, with scenarios belonging to one company and with the tools to be used in other contexts.

The example investigation deals with the automotive domain, where, the EU ecopolicy distinguishes severe on duty demands, to be achieved through voluntary agreements with the users, and mandatory recovery targets, under total carmaker's responsibility. The idea is to assign tags to the components, in view to record the cumulated damage, for on-duty maintenance and end-of-life evaluation, Figure 1. In 
terms of cost, the in-progress technology evolution and the extended versatility, the resort to Radio Frequency Identification Device, RFID, is privileged, as ideal means for the component traceability by history, use modes/styles and cumulated issues storing. At the moment, the amount of inscribed data in RFID is small; to remove the limitation, a remote on-board intelligent module ought to be added, with the capability: - to acquire the data from the on-the-field sensors; - to process the measurements, obtaining characterising signatures, assessing operation modes, severity indices, etc., writing pertinent message on the label; - to read/write the information, for subsequent up-dating or completion.

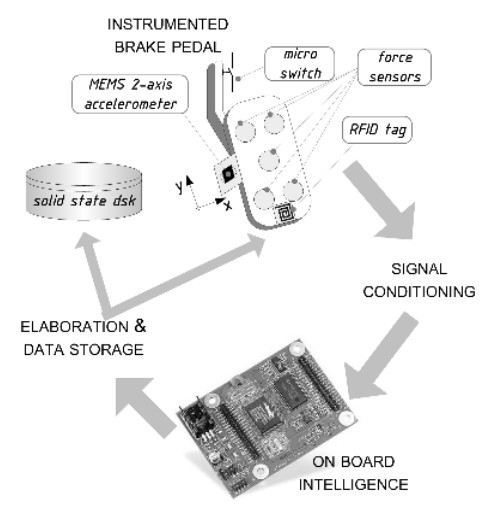

Figure 1 The brake pedal intelligence and communication set-up.

On the remote module, a virtual instrument is programmed, having in charge to compute and to store two different kinds of knowledge: the short-term data, providing more details on the on-duty conditions and on the operation modes of the components, which, due to their redundancy, need to be vaulted into external archives and saved at regular time intervals; the long-term data, giving synthetic features of the item overall life, which are written on the RFID. Looking, for example purpose, to the car braking pedal, Figure 1, the on-process information frame exploits the front instruments, monitoring [15]:

- the number of pedal actuations, shown by a counter driven by micro-switches;

- the averaged pedal stroke, combining micro-switches and timers;

- the averaged pedal stroke variance, computed in parallel with the said data;

- the actuation law, given by MEMS accelerometers and subsequent processing;

- more specific operation «styles», such as high/weak strokes, long-lasting/iterated features, etc., reckoned by detecting and coding the signatures corresponding to the singled out drivers' habits.

The module is integrated in the car computer: the short-term data are collected and checked during the standard maintenance and conformance assessment operations. This way, fully transparent information flow is created, assuring process visibility to the different stakeholders: car-makers, users, car-repairing shops, carbreakers and certifying/controlling bodies.

The healing/restoration features are fulfilled with regard to the specific productservice delivery. One distinguishes the embedded, for knowledge build-up, from the ambient intelligence, for communication help. The ambient intelligence is above all 
relevant for the processing frame (not the component itself), and for the friendliness of the information flow, Figure 2. The main benefits are the following [15]:

- to concentrate information on supplied functions and to create lifestyle mind;

- to enable information sharing, and easier eco-consistency data management;

- to fulfil in real-time and intelligent ways the conformance-to-specification tests;

- to automatically manage the product lifecycle and service provision checks;

- to exploit the supply chain product/process carried/acquired/computed data.

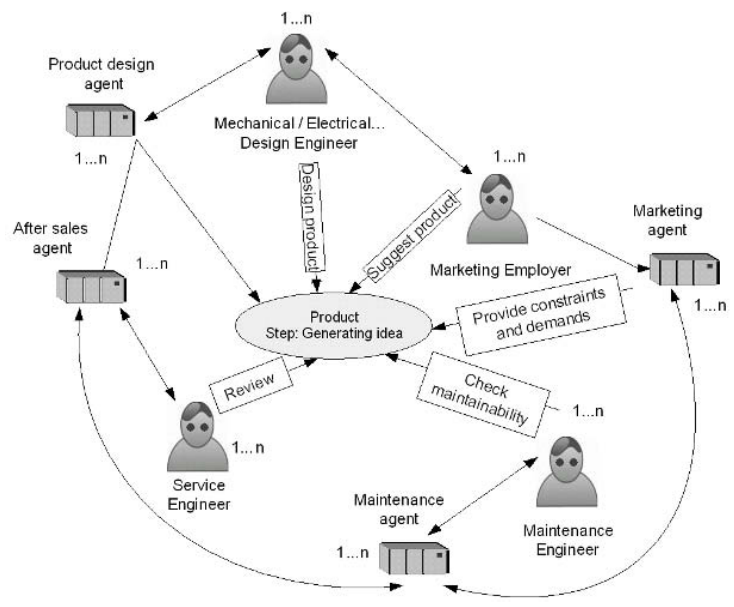

Figure 2 The PLM-SE set-up, with Ambient Intelligence aids.

The ambient intelligence empowers the PLM-SE, once large, heterogeneous, distributed frames, built on multiple-function platforms, support the delivery of value added services to clients. The ambient intelligence authorises easy interaction, with plain language or any other means a non-computer specialist uses to communicate. The remote service is built on standard blocks, Figure 2, equivalently given by operators or computer agents, typically, split into:

- the common knowledge-base, with the product-process-environment-enterprise data, the design up-dated reference, combining product lifecycle management PLM and service engineering SE frames;

- the set-up module, or data-base manager, with graphic interface to help the user to follow and understand the process under observation, with related diagnostics frame, and to make the best use of it, by supporting the definition, modification, storing, deletion, etc., of the common knowledge-base elements;

- the information processing module, to map the input (supplied by the distributed sensors) into the common knowledge-base elements, following the idea that the ambient data can be expressed into any format and the detection/transmission is operated automatically, without explicit peripheral concern;

- the diagnostic engine, providing the interactive problem-solving support to the users with resort to heuristic rules, case-driven reasoning, etc. and connects, by means of the shared broker architecture, to the common knowledge-base, to make decisions and to friendly acknowledge diagnostics signatures;

- the client support module, core of the remote diagnostics with the products data 
(operation, maintenance, disassembly, etc.), for process instantiation, assuring that the operation unit sees the virtual image of network (this allows protected access to the certification/supervision bodies);

- the knowledge analysis module, doing data the restitution and reporting, by spot entries (database query, etc.), statistical outcomes (Pareto charts, etc.), lifestyle analyses (on-duty reports, etc.), etc., with link to the common knowledge-base, through the client support module.

The example case shows how the extended enterprises, with domain proprietary technologies, turn into handy product-service dealers, fulfilling lifecycle support, provided that information/communication aids specialise into PLM-SE tools, fully developed at the design phase [8].

The instrumental set-up, according to above sketched lines, is developed with in mind the emerging demands in terms of the carmakers' extended responsibility, with unequivocal involvement in the reverse logistics and in the re-engineering tasks, and relevant engagement in the service engineering, as the explicit origin of the product data, or, with higher commitment, as the direct provider of the lifecycle backing. These new facts require rethinking the competition paradigms of the automotive industry, and, of course, object of special concern among the worldwide carmakers. The instrumental set-up, moreover, is also worthy help in assessing the users' behavioural accountability. The lifecycle monitored data supply objective checks whether or not the driver has operated with full compliance of the manufacturer's notices or warnings and the law rules or instructions. The achieved transparency is important for the contractual bonds and the third-people protection, providing clear access to the users' liability, in case of accidents, when, e.g., the assurance is required to have objective reports on the elapsed occurrences, with resort to the records that document, in the present example, if, when, how long and by which trend the pedal is actuated.

\section{Virtual-Enterprise for Lifestyle Innovation}

The EU eco-policy tends to expand the carmakers' responsibility, imposing the ecorules for new deliveries and the free take-back of end-of-life items, subdued to compulsory recovery targets. This was declared with over ten years advance, but apparently only in Germany the 2P2E approach coherently leads to lean structured extended enterprises that guarantee the free take-back duties. Elsewhere, the virtual enterprise solution seems factual issue, and the recovery (reuse, recycle) compulsory targets are ruled by governmental agencies or steered by collaborating brokers. The EU targets are strict:

- from 01.01 .2006 : $85 \%$ by weigh of the vehicle has to be recovered or recycled; the $10 \%$ can be dumped to landfills (after suitable neutralisation), and the $5 \%$ can be used as auxiliary fuel;

- from 01.01.2015: the figures are modified, allowing 10\% for fuel use, but only 5\% to landfills.

The reverse logistics, Figure 3, develops with unified information flow, with endof-life recovery ruled by the carmakers PLM-RL data-bases, actually, collected by the automotive [16], covering some 1000 vehicle types of 25 producers, listing 
around 46000 pieces, with ample visual and analytical data. The EU acts require involving properly authorised treatment facilities, ATF, which guarantee the backward process under the three parties scheme [3]:

- purveyors, covering the supply-chain: materials provision, items manufacture, lifecycle up-keeping, backward recovery; the eco-responsibility is dealt with by clustering several firms in alliance of co-operating multi-sectional interest units;

- users, purchasing products-services, to profit of provided functions with reliability figure close to one; the payments include conformance certification at the point of service, after tax collection against tangibles depletion and pollutants release;

- supervisors, assuring third party checks of environment and society protection; the certifying bodies report to governmental authorities and use standards, having access to the extended artefacts life-cycle data-bases.

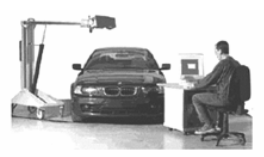

MANAGEMENT SYSTEM

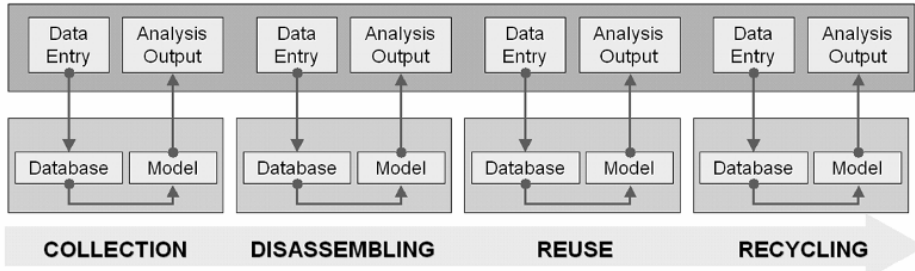

Figure 3 The knowledge build-up in end-of-life vehicles recovery.

The ATF are, surely, out of the core business of usual carmakers, and extended enterprises, with explicit mind on reverse logistics effectiveness, [17,18], are substituted by:

- governmental agencies overseeing the recovery (reuse, recycle) duties, through deposit-refund schemes, so that the reverse logistics is (top-down) financed by taxing each new car put in the market;

- specialised 'recovery rulers', who replace the carmaker, having broker's activity to select the reverse logistics facilities/functions, collecting from the users, the (bottom-up) visible fees.

The UE rules accepts these different set-ups, and only the German carmakers tend to become extended enterprises. The agency scheme is used in Sweden; the broker alternative, in the Netherlands. The first set-up is winning, but assumes pioneering work with coherent $2 \mathrm{P} 2 \mathrm{E}$ issues, by feeding back the design-forrecovery scopes. On the short span, the return on investment is not easily assessed, in terms of the individual manufacturer and country. The Netherlands solution is highly efficient (today recovery visible fees, as low as $15 €,[19]$ ). Anyway, the domain knowledge build-up, Figure 3, needs to consider the M\&SF, addressing the PLM-RL tools, up to the suited details. The virtual enterprise solution, thereafter, could result especially efficient, replacing the German 'firm theory' (the make-orbuy paradigm), by the 'enterprises creation' alternative, assuming: 
- to trade facilities, functions, technologies and related integration protocols, with helpful access, negotiation, assembling and management abilities;

- to establish the selection, acquisition and merging brokerage area, wide enough to grant competitive choices, and efficiently ruled to keep steadiness.

The reverse logistics typifies by like information flows, but differs on value chain. The extended enterprise incorporates in the offer all demands necessary to put the car on the market (call-back included). On the opposite side, the governmental agency manages economic incentive (deposit/refund), to finance the recovery, fulfilled under permission ruling. In between, the virtual setting builds, using:

- a logistic network, with collecting and transport means, storage points, handling and inspection devices, joined to information flow for acquisition and recording;

- dismantling shops for safe parts recovering and storing, with forwarding of left hulks to suitably located shredding facilities, for grinding to tiny pieces;

- sorting plants, to pull out metals (ferrous alloys, stainless steels, aluminium alloys, brass, etc.), different plastics, glass, etc., and safe incineration plants;

- parts-reuse and materials-recycle tracks, for service engineering maintenance and design and manufacture practices with secondary materials provisioning.

The listed functions/facilities are heterogeneous, with the authorised treatment facility, ATF, as the characterising step, gathered around buffering/dismantling shops, Figure 4. The brokerage alternative does not add administrative costs, and only assemble the necessary processing partners, with visibility of the mandatory targets achievement $[12,20]$.
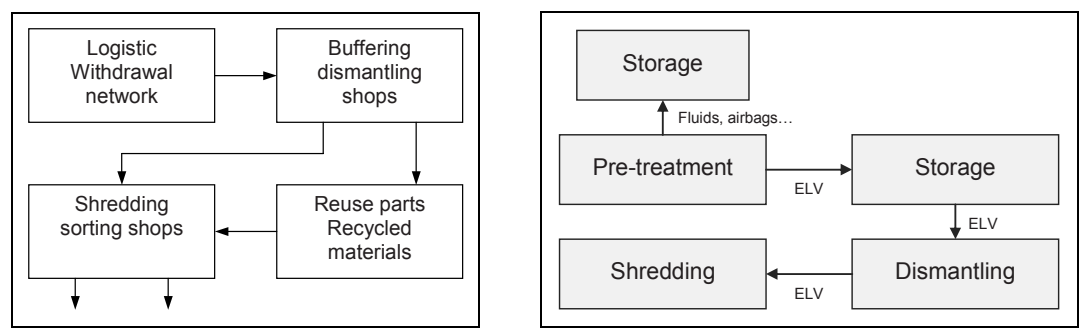

Figure 4 The reverse logistics flow and example dismantlig shop.

The authorised treatment facility, ATF, is node of the networked concern, built, with broker help, from the function/facility market. The virtual enterprise ruler, devising business projects, and demanding the gathering of qualified partners, has, just, intermediation duties. The assembly allows the facilities/functions collection, with varying goals and technical heterogeneity, but capable of efficient provision in the given business. The all implies the advanced features of net concerns. This does not lead to a corporation and is better identified by a manufacture/service cluster, possibly, time-varying, so that the 'recovery rulers' is identified by the supply chain, and is the legal entity, having up-dated below architectures of facilities/functions providers. It happens that the car user interacts at the point-ofsale with a dealer linked to a given partners' set, and at the end-of-life, the entitled 'recovery rulers' corresponds a to modified partners' set [21].

The virtual enterprise solution does not lead to completely different set-ups. The 
related issues, moreover, are not even new, as they simply separate the 'brand', from the production/service facilities. The difference comes out from the lifecycle obligation, engaging the firm by respect to the society, notably, for the eco-duties. In the facility/function market, the brokerage helps building alliances, having the skill and competency in the reverse logistics only, while the extended enterprise is involved in the integrated $2 \mathrm{P} 2 \mathrm{E}$ design, for everything that concerns the business decision-making (choice, negotiation and integration) operation all over the supply chain. The broker role has, instead, bottom-up value, enhancing the organisation effectiveness, strengthening the trust between partners and assuring the supply chain stability (also in legal terms). The sketched frame is consistent outcome of knowledge-driven entrepreneurial assets, where access to suited net-concerns is factual prerequisite. If the industrial context cannot afford the $2 \mathrm{P} 2 \mathrm{E}$ issues up to extended enterprises, the $2 \mathrm{E}$ issues permit to combine recovery facilities/functions, which are able to fulfil the environmental acts, by bottom-up ATF deployment.

\section{Conclusion}

The product-process-environment-enterprise, $2 \mathrm{P} 2 \mathrm{E}$, practice is deemed to extend the product-process, $2 \mathrm{P}$, simultaneous engineering, turning the value chain on the lifestyle externalities. The new PLM tools distinguish by the addition of on-duty service engineering, and reverse logistics, with the pertinent $M \& S F$ supplements. The design-for-manufacturing, $D f M$, design-for-assembly, $D f A$, etc., scopes shall expand over the new design-for-disassembly, $D f D$, design-for-recovery, $D f R$, etc., ones, which need to establish since the early product ideation steps. The business idea shall include recovery, reuse and recycle of products, parts and materials, to minimise the tangible resources spoil and to maximise the supply chain efficiency. The full M\&SF identification shall enable the designers to explore and to analyse the reverse logistics as worthy option, to enhance the tangibles productivity and the environmental protection, for company liability and profitability. The issue brings to the extended enterprise organisation, specialised in product-service. Today, the EU eco-regulation has enacted mandatory recovery (reuse, recycle) targets within the manufacturers' responsibility. The rules apply to the automotive industry, but not all carmakers have the extended enterprise in mind. In default, the virtual enterprise goal might result effective, specialising the environment-enterprise, $2 \mathrm{E}$, design whether the proper PLM-RL aids allow the 'recovery ruler' brokerage to integrate the right functions/facilities. The product lifestyle design is, once again, the enabling option, supporting the innovation.

In general, proper exploitation of $M \& S F$ description will be the way of improving the effectiveness of the manufacture businesses, to reach the best balance of all constraints in designing, developing, producing, supporting, servicing, recovering and recycling products. Cost and time reduction, customer satisfaction, lifecycle responsibility, environmental protection and resources conservativeness have to be part of super-models, with algorithmic and heuristic blocks, balanced by captured knowledge, virtual tests, on-line analyses and designer's decision making. The PLM aids will support the best practice, from the ideation, up to operation and callback, with waste handling and remediation. Every requirement is shown to the 
users, and transparent to the authorities, so to assess the resource productivity. The federated modelling approach becomes dynamic, with learning a bit at step issues and training the design teams to combine views and integrate functions.

\section{References}

1. Michelini R.C., Razzoli R.P.: Product-service for environmental safeguard: a metric to sustainability. Intl. J. Resources Conservation and Recycling, vol. 42(1), pp. 83-98 (2004).

2. Michelini R.C., Razzoli R.P.: Product-service eco-design: knowledge-based infrastructures. Intl. J. Cleaner Production, vol. 12, n 4, pp. 415-428 (2004).

3. Michelini R.C.: Knowledge entrepreneurship and sustainable growth, p. 390, Nova, Hauppauge (2008).

4. Michelini R.C., Acaccia G.M., Callegari M., Molfino R.M., Razzoli R.P.: Artefact integration by concurrent enterprises and productive break-up. Jacucci G., Olling G.J., Preiss K., Wozny M. Eds.: 'Manufacturing Globalisation in the Digital Communication Era, pp. 221-234, Kluwer, Boston (1999).

5. Michelini R.C., Kovàcs G.L.: Information infrastructures and sustainability. In: Camarinha Matos L., Ed., Emerging Solutions for Future Manufacturing Systems, pp. 347-356, Springer (2005).

6. Michelini R.C., Razzoli R.P.: Collaborative networked organisations for eco-consistent supplychains. In Putnik\&Cunha, Eds., Virtual Enterprise Integration, pp. 45-77, IGI Press (2005).

7. Michelini R.C., Acaccia G.M., Callegari M., Molfino R.M., Razzoli R.P.: Shop controller-andmanager for intelligent manufacture. S. Tzafestas Ed.: 'Management and Control of Manufacturing Systems', pp. 219-254, Springer (1997).

8. Acaccia G.M., Kopàcsi S., Kovàcs G., Michelini R.C., Razzoli R.P.: Service engineering and extended artefact delivery. In: G.D. Putnik M.M. Cunha Eds., Knowledge Management in Virtual Organizations, IDEA Group Pub., pp. 24-68, IGI Press (2007).

9. Acaccia G.M., Michelini R.C., Penzo L., Qualich N.: Automotive systems: end-of-life vehicles dismantling facilities. 8th ESDA ASME Conf., pp.1-8, Torino July 4-7 (2006).

10. Anufriev A., Kopàcsi S., Kovàcs G., Michelini R.C.: Ambient intelligence as enabling aid for modern business paradigms. J. Robotics Comp. Integr. Man., n. 2, pp. 242-256 (2007).

11. Borg J.C., Farrugia Ph.J., Camilleri K.P.: Knowledge-intensive design technology. Springer, IFIP Series, pp. 1-200 (2004).

12. Cunha M.M., Putnik G.D.: Agile virtual enterprises: implementation and management support. IDEA Group Pub. Hershey (2006).

13. Belotti V., Michelini R.C., Razzoli R.P.: Remote overseeing of car brake pedal for reuse/recycle and pre-collision history investigation. Intl. Conf. Remote Engineering and Virtual Instrumentation REV2007, Intl. Assoc. of Online Eng., Porto, June 24-27 (2007).

14. Kovàcs G., Kopàcsi S., Haidegger G., Michelini R.C.: Ambient intelligence in product lifecycle design. J. Eng. Appl. of Artificial Intelligence, vol. 19, n. 8, pp. 953-965 (2006).

15. Michelini R.C., Razzoli R.P.: Ubiquitous computing and communication for product monitoring. M. Khosrow-Pour, Ed.: Encyclop. Information Sci. and Techn., 2nd Ed., IDEA Group (2007).

16. IDIS, International Dismantling Information System. http://www.idis2.com, (2008).

17. Acaccia G.M., Michelini R.C., Qualich N.: Sustainable engineering management: end-of-life vehicles with recovery in mind. World Review Sci., Techn. and Sustain. Dev., vol. 4, n. 4/5 (2007).

18. Acaccia G.M., Michelini R.C., Penzo L., Qualich N.: Reverse logistics and resource recovery: modelling car dismantling facilities. World Review Sci., Techn. and Sustain. Dev., vol. 4, n. 2/3 (2007).

19. ARN, Auto Recycling Nederland. http://www.arn.nl/ (2008).

20. Dickhoff H., Lackes R., Reese J.: Supply chain management and reverse logistics. Springer Verlag, pp. xviii-426, Berlin (2004).

21. Blumberg D.F.: Introduction to management of reverse logistics and closed loop supply chain processes. CRC Press, pp. 1-296 (2004). 